\title{
Dual Heat Pulse, Dual Layer Thermal Protection System Sizing Analysis and Trade Studies for Human Mars Entry Descent and Landing
}

\author{
Mary Kathleen McGuire \\ NASA Ames Research Center, Moffett Field, CA 94035-1000
}

\begin{abstract}
NASA has been recently updating design reference missions for the human exploration of Mars and evaluating the technology investments required to do so. The first of these started in January 2007 and developed the Mars Design Reference Architecture 5.0 (DRA5). As part of DRA5, Thermal Protection System (TPS) sizing analysis was performed on a mid $\mathrm{L} / \mathrm{D}$ rigid aeroshell undergoing a dual heat pulse (aerocapture and atmospheric entry) trajectory. The DRA5 TPS subteam determined that using traditional monolithic ablator systems would be mass expensive. They proposed a new dual-layer TPS concept utilizing an ablator atop a low thermal conductivity insulative substrate to address the issue. Using existing thermal response models for an ablator and insulative tile, preliminary hand analysis of the dual layer concept at a few key heating points indicated that the concept showed potential to reduce TPS masses and warranted further study. In FY09, the followon Entry, Descent and Landing Systems Analysis (EDL-SA) project continued by focusing on Exploration-class cargo or crewed missions requiring 10 to 50 metric tons of landed payload. The TPS subteam advanced the preliminary dual-layer TPS analysis by developing a new process and updated TPS sizing code to rapidly evaluate mass-optimized, full body sizing for a dual layer TPS that is capable of dual heat pulse performance. This paper describes the process and presents the results of the EDL-SA FY09 dual-layer TPS analyses on the rigid mid L/D aeroshell. Additionally, several trade studies were conducted with the sizing code to evaluate the impact of various design factors, assumptions and margins.
\end{abstract}

\section{Nomenclature}

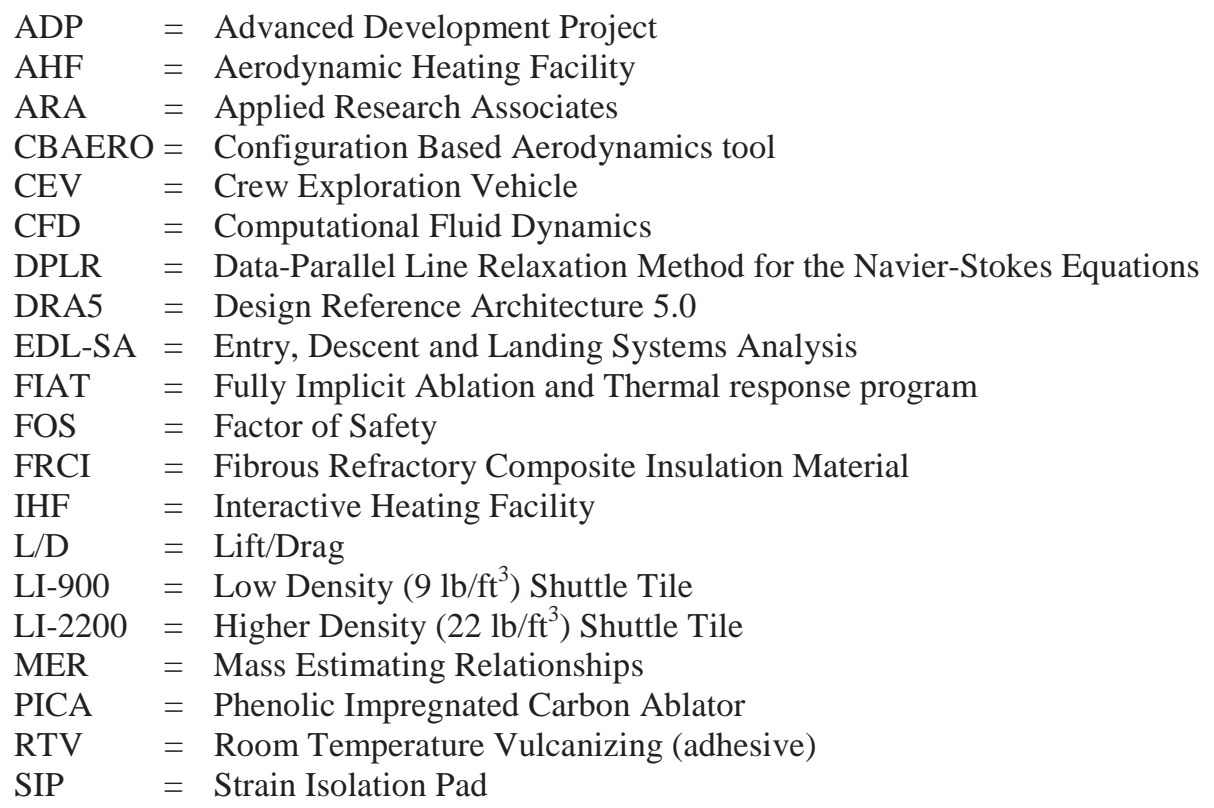

\footnotetext{
${ }^{1}$ Aerospace Engineer, Systems Analysis Branch - AUS, MS 258-1, Member AIAA.
} 


$\begin{array}{ll}\text { SLA-561 } & =\text { Super Lightweight Ablator } \\ \text { TPS } & =\text { Thermal Protection System } \\ \text { TPSSizer } & =\text { Thermal Protection System Sizing program } \\ \text { TRL } & =\text { Technology Readiness Level }\end{array}$

\section{Introduction}

$\mathrm{N}$ ASA has been updating its human Mars Design Reference missions and evaluating the technology investments required to enable human and large payload missions to the surface of Mars. ${ }^{1,2}$ The first part of these studies, started in January 2007, developed the Mars Design Reference Architecture 5.0 (DRA5) ${ }^{3}$ which examined the systems required to enable the delivery of 40 metric ton payloads to the surface of Mars. As part of that study, Thermal Protection System (TPS) sizing analysis was performed on a 10 by 29 meter mid L/D rigid aeroshell vehicle. On arrival at Mars, the vehicle would experience a dual heat pulse trajectory defined as heating during aerocapture followed by a cool off on-orbit and finally a second heating during atmospheric entry. Using Phenolic Impregnated Carbon Ablator (PICA) as an example ablator, the DRA5 TPS subteam determined that the amount of traditional monolithic ablator system required to protect a mid L/D rigid aeroshell during dual heat pulse heating would be mass expensive because of the relatively high density of ablative TPS materials. To address this issue, the subteam conceived of a new dual-layer TPS utilizing an ablator atop a low thermal conductivity, low density substrate such as Shuttle tile material or SLA-561. Individually, these TPS materials are at a high TRL, but a dual layer TPS system made of these materials had not been evaluated or tested. Using existing thermal response models for an ablator (PICA) and a Shuttle tile (LI-900), preliminary hand analysis of the dual layer concept at three body points indicated that the concept could reduce TPS masses by about 27\% (not accounting for the mass of the TPS attachments).

In FY09 the follow-on Entry Descent and Landing Systems Analysis (EDL-SA) project focused on Explorationclass cargo or crewed missions to Mars requiring 10 to 50 metric tons of landed payload. ${ }^{4}$ As part of this effort, the TPS subteam focused on advancing the preliminary dual-layer TPS analysis by automating the mass optimization of dual layer, dual heat pulse whole-body TPS analysis. To do so, a process was developed and the TPSSizer ${ }^{5}$ code was upgraded to perform dual-layer TPS thickness optimizations and mass estimates for multiple zones on a vehicle. The results of applying the upgraded code predicted that PICA atop the LI-900 Shuttle tile material is capable of reducing the windward TPS mass by 37\%, not accounting for TPS attachments or weight-growth allowance. Additionally, the upgraded TPSSizer was used to conduct several trade studies to evaluate the impact of various design factors, assumptions and margins.

A new TPS manufacturing scheme using a large honeycomb attachment of approximately $5 \mathrm{~cm}$ by $5 \mathrm{~cm}$ square cells was developed by the Orion Thermal Protection System Advanced Development Project (Orion TPS ADP), to enable manufacturing and integration of multiple TPS materials into a heat shield for large entry capsules (typical dimensions of 5-30 meters). Thermal testing ${ }^{8}$ of the new TPS concept was conducted to validate the dual layer, dual heat pulse concept, and adds credence to the analysis reported here. Simulation of the dual heat pulse profile was performed by first exposing models in the NASA Ames Interactive Heating Facility (IHF) arc jet at $438 \mathrm{~W} / \mathrm{cm}^{2}$ and $28 \mathrm{kPa}$ pressure for 75 seconds to simulate aerocapture. Next, the post-tested models were stored for several months to simulate cool down in Mars orbit. The model was then exposed to $153 \mathrm{~W} / \mathrm{cm}^{2}$ and $5 \mathrm{kPa}$ in the Ames Aerodynamic Heating Facility (AHF) to simulate the out-of-orbit entry heat pulse.

Dual layer TPS such as PICA over Shuttle tile in a large honeycomb concept is very attractive, not only for large mass human systems to Mars but for future aerocapture and entry probe missions to all destinations where large heat loads, and in particular dual heat pulse missions, are encountered.

\section{Computational Approach}

Estimated thermal response models were used in the sizing analysis of the thermal protection systems (TPS) needed for a 10 by 29 meter rigid mid-L/D aeroshells. The sizing was performed on a dual heat pulse mission (aerocapture, cool down in orbit and out-of orbit entry). The sizing analysis is based on the tools and practices developed by the Orion TPS ADP. The TPS sizing tool, TPSSizer ${ }^{5}$ (which makes use of the ablative thermal analysis tool FIAT ${ }^{9}$ ) was extended for EDL-SA to include the capability to size dual layer TPS. The margins applied to TPS masses were developed based on the Orion TPS ADP experience ${ }^{10}$ and are summarized in Table 1. 


\section{A. TPS Material Stack and Analysis Process}

The TPS material stack used for the mid L/D aeroshell analysis is shown in Figure 1. The tile was attached to the substructure with a standard RTV/SIP/RTV configuration. The analysis substructure was a titanium plate and represents the thermal mass of typical aeroshell thermal masses. The ablator was modeled directly above the tile. No adhesive or attachment between the ablator and tile was modeled. This was considered to be sufficiently conservative from a thermal perspective for this analysis cycle.

The material splitlines for the mid L/D vehicle are

Table 1. TPS Sizing Margins

\begin{tabular}{|l|l|}
\hline \hline Parameter & Value \\
\hline \hline Initial Temperature & $70^{\circ} \mathrm{F}$ \\
\hline Radiation Sink Temperature & $70^{\circ} \mathrm{F}$ \\
\hline Allowable Bondline Temperature & $550^{\circ} \mathrm{F}$ \\
\hline Blowing Factor & 0.4 \\
\hline Ablator Fail Lien & $50 \%$ \\
\hline Thermal Margin & $108^{\circ} \mathrm{F}$ \\
\hline Gap Heating Factor & 1.0 \\
\hline Recession Uncertainty, Default FOS & $1.2,1.1$ \\
\hline \hline
\end{tabular}

determined by the maximum temperature seen at each location during aerocapture and entry. They are shown in Figure 2. The leeward sections are tile only and were sized by a transient run that included both aerocapture and entry with a long on-orbit cool off between. For the windward dual layer sections, it is assumed that the on-orbit cool off between the aerocapture and entry phases is sufficiently long enough for the TPS system to cool completely to the initial temperature. It is also assumed that the ablator is needed to protect the tile during aerocapture, but is not needed during entry. So for the windward dual layer TPS analyses, the aerocapture and entry phases was separated and run in two steps. For the first step, the ablator was removed from the model and the tile layer was sized to survive the entry environment while maintaining the allowable bondline temperature at the tile/RTV interface. For the second step, the ablator was reattached to the model. The ablator was then sized to maintain the tile allowable surface temperature at the ablator/tile interface (as well as the allowable bondline temperature at the tile/RTV interface) during

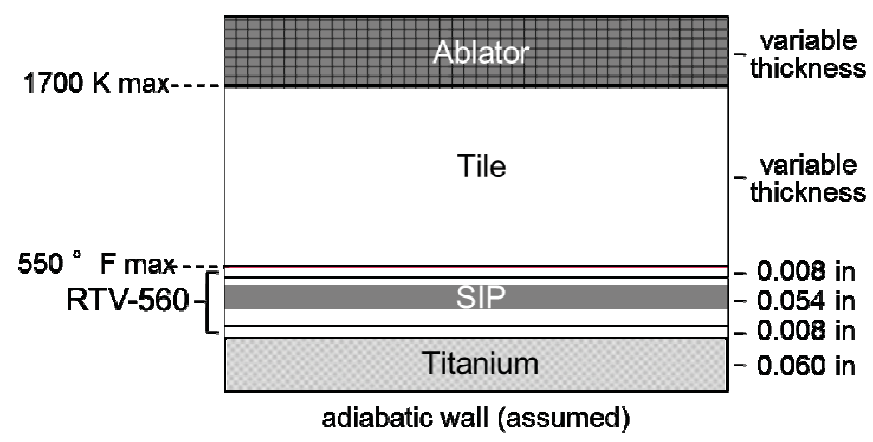

Figure 1. Mid L/D Rigid Aeroshell TPS Stack

aerocapture. The TPSSizer code was upgraded to run these sizing steps automatically updating the TPS stack thicknesses as each step was completed. This facilitated the running of whole vehicle TPS sizing analyses automatically and enabled the execution of multiple trade studies.

Note, that the above described analysis method assumes that the ablator is needed to protect the tiles in a duallayer stack during the aerocapture phase only. However, the validation testing of the dual heat pulse, dual layer concept presented in Ref. 8 shows some slumping of the LI-900 tile at the peak entry heating rates once the PICA has ablated away. Therefore, future analysis should consider leaving a thin amount of ablator (or char) at the end of aerocapture to protect the tile during entry at the highest heat flux areas of the windward dual-layer section. The TPSSizer code is being further upgraded to enable analysis that would

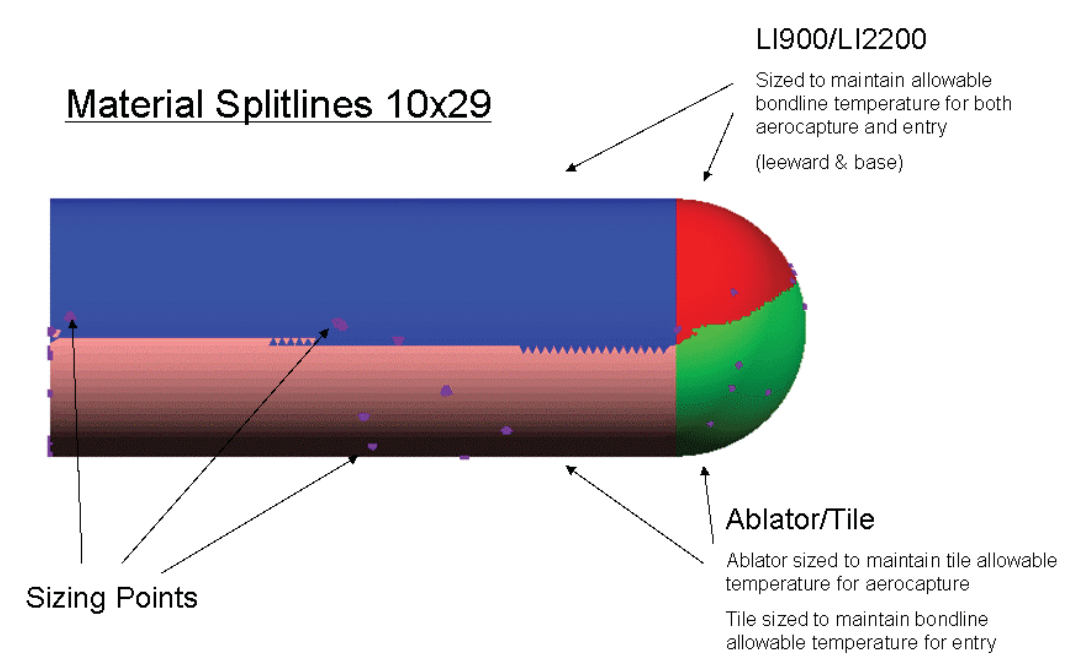

Figure 2. Mid L/D Rigid Aeroshell Material Splitlines

American Institute of Aeronautics and Astronautics 
maintain some amount of ablator for the atmospheric entry portion of the mission if it is necessary.

\section{B. Aerothermal Environment}

The aerothermal environments for the mid L/D rigid aeroshell were calculated by the CBAERO ${ }^{11}$ utility CBTPS using an aerothermal database ${ }^{12}$ (anchored against high fidelity DPLR ${ }^{13}$ CFD) and aerocapture and atmospheric entry trajectories ${ }^{14}$ calculated by the EDL-SA team. The mid L/D aeroshell dual pulse environment for aerocapture and entry is shown in Figure 4, which shows maximum total heating for the aerocapture in red and the entry phase in blue. (The curves are plotted one after the other for visualization, but in reality there is a long on-orbit cooling period between them.) The integrated heatload contour is shown in Figure 3. Fully margined analysis indicates that the mid $\mathrm{L} / \mathrm{D}$ aeroshell experiences around $450 \mathrm{~W} / \mathrm{cm}^{2}$ during aerocapture and $120 \mathrm{~W} / \mathrm{cm}^{2}$ during entry.

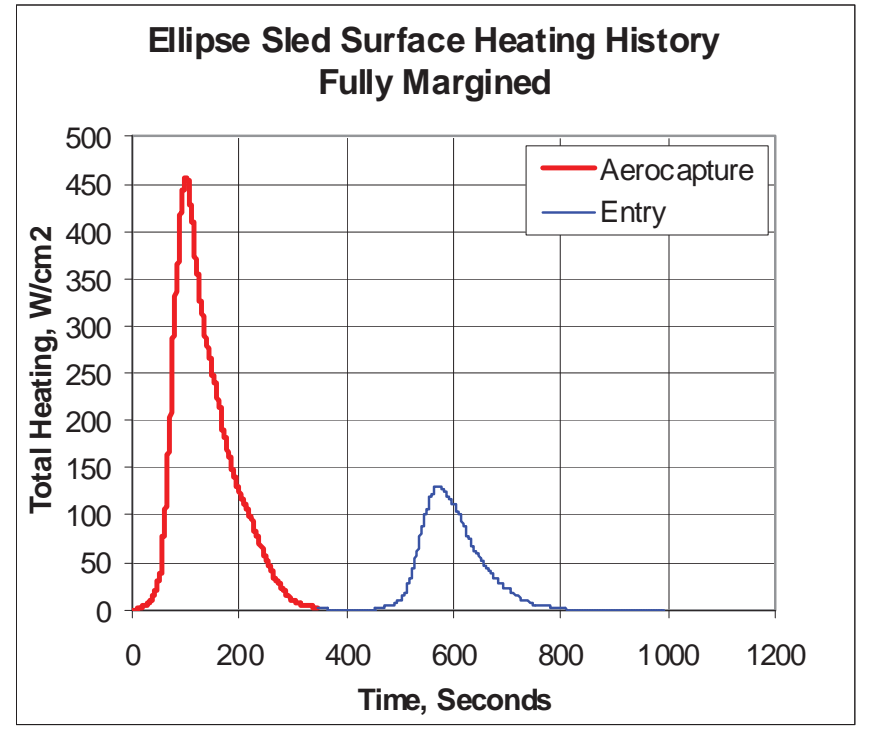

Figure 4. Mid L/D Rigid Aeroshell Dual Pulse Surface Heating History (Fully Margined)
Integrated Heatload Contour (Full Margins)

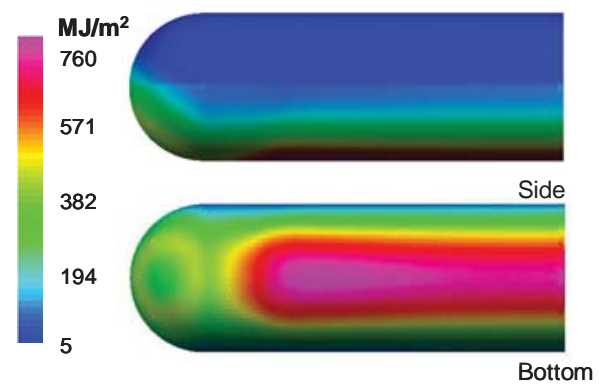

Figure 3. Mid L/D Rigid Aeroshell Dual Pulse Integrated Heatload Contour (Fully Margined)

\section{Comparison to Preliminary Analysis Done During DRM5}

The original analysis of a dual layer system for DRA $5^{3}$ was performed on a material stack which consisted of the ablator PICA on top of the insulative tile FRCI (rather than LI-900). The limit set for FRCI surface temperature was 1700 Kelvin or $3060{ }^{\circ}$ Rankine. (Rankine is used in this section because the DRM5 plot to be discussed measures temperature in Rankine.) At the time the DRA5 analysis was performed, the ablative TPS analysis code FIAT would fail if the outer ablative layer completely recessed away. For this reason, the ablative layer could not be optimized by a FIAT optimization analysis to maintain the allowable FRCI surface temperature. As a work-around, in order to insure that the FRCI was not heated above this temperature, the analyst examined the radiation equilibrium temperature profile and determined the time in the trajectory after which the surface temperature would be below $3060{ }^{\circ}$ Rankine. Then, by hand, several thicknesses of PICA were run in FIAT until the analyst was able to match the time of complete PICA recession (and failure of the FIAT code) to the time selected from the radiation equilibrium history. The surface temperature of the PICA over FRCI analysis for DRM5 is shown in Figure 5.

For the FY09 analysis cycle a new version of FIAT was available which allows for the outer ablative TPS layer to ablate away. With this new version of FIAT, the thickness of the PICA can be optimized to maintain the FRCI allowable temperature even if the PICA completely recedes away at some point in the transient analysis. For the comparison to DRM5, current results for the surface temperature of PICA over FRCI are shown in Figure 6.

In both Figure 5 and Figure 6 a distinct bump can be seen in the surface temperature once the ablative layer has receded away. In the DRM5 analysis this occurred slightly later than required and the FRCI surface temperature never actually reached its limit of $3060^{\circ}$ Rankine. This means that using the radiation sink temperature time history was an overly conservative way to determine how much PICA was required. For the new analysis method, it can be 
seen that the surface temperature right at the burn-through bump hits $3060^{\circ}$ Rankine, demonstrating the optimization improvement.

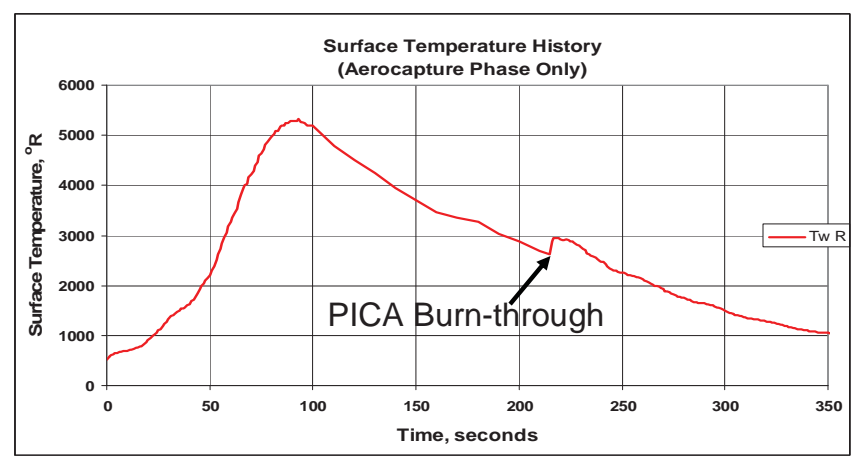

Figure 5. Surface temperature history for DRM5 dual layer analysis.

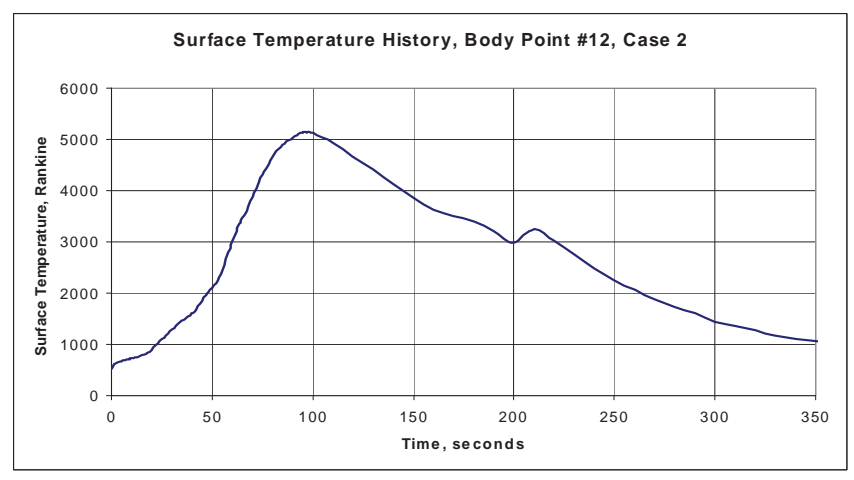

Figure 6. Surface temperature history for current dual layer analysis.

\section{Analysis Results and Discussion}

For FY09 EDL-SA updated the analysis of the rigid mid L/D vehicle.

\section{A. TPS Analysis Results Not Including Attachments}

Results for the mid L/D aeroshell TPS sizing analysis are shown in Table 2. Analyses were run for the ablator PICA over two different tiles, LI-2200 and LI-900. For comparison, a case was also run with PICA only on the windward surface of the vehicle. The results show that if the lightweight LI-900 tile is used with PICA, there is an estimated TPS mass savings over the whole vehicle of 34\%. These estimates do not include masses for the attachment of the ablator to the tile or for any structure to hold the TPS.

Table 2. Mid L/D Aeroshell TPS Mass Estimates (Not including attachment or WGA)

\begin{tabular}{|l|l|l|l|l|l|}
\hline \hline Windward TPS & PICA Only & Dual Layer PICA/LI-2200 & Dual Layer PICA/LI-900 \\
\hline & Mass, kg & Mass, kg & Savings & Mass, kg & Savings \\
\hline \hline Nose Windward & 1670 & 1350 & $19 \%$ & 1000 & $40 \%$ \\
\hline Body Windward & 8750 & 7020 & $20 \%$ & 5580 & $36 \%$ \\
\hline TOTAL Vehicle TPS* & 11260 & 9210 & $18 \%$ & 7420 & $34 \%$ \\
\hline \hline * Includes Leeward Tiles
\end{tabular}




\section{B. Estimates for Attachment Weights}

Estimates for TPS system attachment weights were performed and are shown in Table 3. Two attachment methods were considered, a shuttle like tile system with $25.4 \mathrm{~cm}$ square tiles and a honeycomb system with $5 \mathrm{~cm}$ square blocks bonded into a honeycomb, which was also bonded to the substructure. The $5 \mathrm{~cm}$ by $5 \mathrm{~cm}$ honeycomb system estimates were made by scaling measured masses from Applied Research Associates, ARA ${ }^{6}$ for $5 \mathrm{~cm}$ thick PICA blocks in phenolic impregnated silica fabric honeycomb with RTV on 5 sides of the PICA blocks. (Note, the "TPS Mass" column differs slightly from the total values in Table 2 because mass was removed for the gaps and the volume calculations were updated to account for the curvature of the vehicle). The Shuttle-like tile systems are considered to be unrealistic for manufacturing of the dual layer system, so method 2 was discounted. However, method 3 (5 cm blocks in honeycomb) using PICA over LI-900 tiles still shows a 24\% mass savings over PICA alone (method 1). The mass calculations for method 3 were employed in the EDL-SA mid L/D mass estimating relationships (MERs).

Table 3. Mid L/D Rigid Aeroshell, Windward Side Estimated Masses with Attachment.

\begin{tabular}{|l|l|l|l|l|l|l|}
\hline \hline & TPS & Attachment Method & $\begin{array}{l}\text { TPS } \\
\text { Mass, } \\
\text { kg }\end{array}$ & $\begin{array}{l}\text { Attachment } \\
\text { Mass, kg }\end{array}$ & $\begin{array}{l}\text { Total } \\
\text { Mass, } \\
\mathrm{kg}\end{array}$ & Comments \\
\hline \hline 1 & PICA Only & $\begin{array}{l}\text { Shuttle like Tile System } \\
25.4 \mathrm{~cm} \text { tiles } \\
0.07 \text { " RTV gap filler } \\
\text { RTV/SIP/RTV to structure }\end{array}$ & 10,600 & 1,100 & 11,700 & $*$ \\
\hline 2 & PICA/LI-900 & $\begin{array}{l}\text { Shuttle like tiles } \\
25.4 \mathrm{~cm} \text { tiles } \\
0.07 \text { RTV gap filler } \\
\text { RTV/SIP/RTV to structure }\end{array}$ & 6,700 & 900 & 7,600 & $\begin{array}{l}\text { Un-bonded PICA on LI-900 } \\
\text { Unrealistic from } \\
\text { Manufacturing Consideration }\end{array}$ \\
\hline 3 & PICA/LI-900 & $\begin{array}{l}\text { 5 cm HC System } \\
\text { HT424 HC to structure } \\
\text { RTV blocks to HC } \\
\text { RTV blocks to structure }\end{array}$ & 6,500 & 2,900 & 9,400 & $\begin{array}{l}\text { Feasibility demonstrated at } \\
\text { coupon level } \\
\text { 23\% heavier than method 2, } \\
\text { but 24\% lighter than PICA } \\
\text { only }\end{array}$ \\
\hline
\end{tabular}

\section{Trade Studies}

The concept for dual layer, dual heat pulse TPS is new, so the sensitivities are not well known. In order to better characterize the concept, several trade studies were run. Table 4 summarizes the parameters considered in the trade studies.

\section{A. Initial Temperature}

Initial temperature is the temperature to which the material layers in the stack are set at the beginning of the transient thermal analysis. For these analyses, all the material layers are set to the same initial temperature. (However, it could be possible to set a temperature gradient in the stack.) This temperature is normally selected to represent a worst case or highest expected temperature coming out of the passive thermal control analysis from flight or orbit. Initial temperature is important because the higher the initial temperature, the closer the structure will already be to the allowable bondline temperature at the start of the analysis. Lowering the initial temperature will lower the amount of TPS required to maintain a fixed allowable bondline temperature.

Results for dual layer TPS mass sensitivity to initial temperature are shown in Figure 7. The sensitivities are shown for the ablator only, for the tile only and for the total mass of the dual layer system (ablator plus tile). The 
masses are all normalized to the mass at the baseline initial temperature, $70^{\circ} \mathrm{F}$. Figure 7 shows that the ablator mass is not very sensitive to the initial temperature, but the tile mass is quite sensitive. The tile mass sensitivity is relatively linear at an approximately $1.2 \%$ increase in tile mass for every $10^{\circ} \mathrm{F}$ increase in initial temperature. This results in a $0.4 \%$ mass increase in total dual layer system mass per $10^{\circ} \mathrm{F}$ increase in the initial temperature.

Table 4. Assumptions and Margins

\begin{tabular}{|c|c|c|c|}
\hline & $\begin{array}{l}\text { DRM5 } \\
\text { Analysis }\end{array}$ & $\begin{array}{l}\text { Current Analysis } \\
\text { Baseline }\end{array}$ & Sensitivity Range \\
\hline Initial Temperature, Kelvin ( $\left.{ }^{\circ} \mathrm{F}\right)$ & $294(70)$ & $294(70)$ & $1,30,50,90^{\circ} \mathrm{F}$ \\
\hline $\begin{array}{l}\text { Allowable Bondline Temperature, } \\
\left.\text { Kelvin ( }{ }^{\circ} \mathrm{F}\right)\end{array}$ & 523 & $561(550)$ & $500,525,575,600,650,700^{\circ} \mathrm{F}$ \\
\hline $\begin{array}{l}\text { Allowable Tile Temperature, } \\
\text { Kelvin }\end{array}$ & 1700 & 1700 & $1600,1650,1750 \mathrm{~K}$ \\
\hline Blowing Factor & 0.5 & 0.4 & - \\
\hline Ablator Fail Lien & $5 \%$ & $50 \%$ & $5,25,75,100 \%$ \\
\hline Thermal Margin, Kelvin & & 60 & $20,40,80,100$ \\
\hline Structure Thermal Mass & No & Yes, Ti 0.06" & $\begin{array}{l}\text { a. Ti } 0.02,0.04,0.08,0.1^{\prime \prime} \\
\text { b. SS, GRBMI, AL - } 0.06 " \\
\text { c. Ti- honeycomb }\end{array}$ \\
\hline After Landing Thermal Soak out? & Yes \& No & No & $\begin{array}{l}\text { Ejection Sensitivity } \\
\text { (Mach } 0,1.5,2.9,4,5)\end{array}$ \\
\hline $\begin{array}{l}\text { Number of Heat Load Splitlines } \\
\text { per Zone }\end{array}$ & & 5 & $1,2,10,20$ \\
\hline Aerothermal Margins & $\begin{array}{l}\text { CEV June } \\
2007\end{array}$ & $\begin{array}{l}\text { CEV June } 2007 \\
\text { (1.35 conv, } 2.0 \text { Rad) }\end{array}$ & Multiplied by 1.1, 1.2 \\
\hline Dispersion Margins & $\begin{array}{l}\text { CEV June } \\
2007\end{array}$ & $\begin{array}{l}\text { CEV June } 2007 \\
(1.35 \mathrm{HL}, 1.1 \mathrm{HR})\end{array}$ & Multiplied by 1.1, 1.2 \\
\hline Fiber Orientation Considered? & No & No & - \\
\hline Recession Margin (PICA) & & 1.2 & - \\
\hline
\end{tabular}

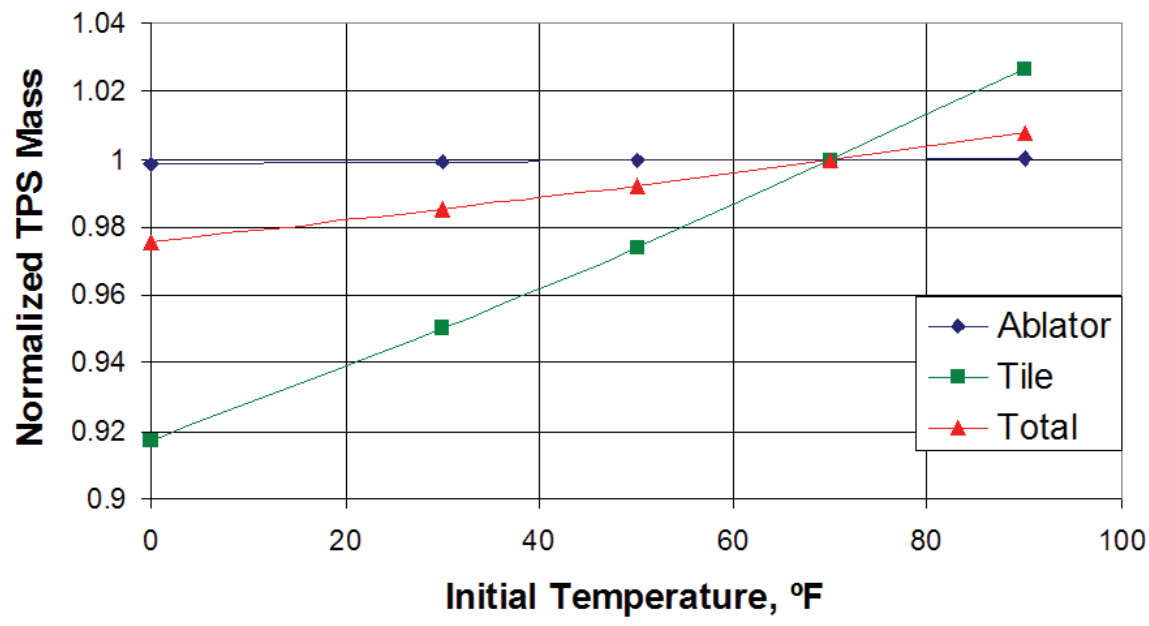

Figure 7. Sensitivity of Dual Layer Mass to Initial Temperature 


\section{B. Allowable Bondline Temperature}

The allowable bondline temperature is normally selected based on material properties of the adhesive or structure used. For these analyses, the baseline value of $550{ }^{\circ} \mathrm{F}$ is the maximum use temperature of RTV. The allowable bondline temperature is a constraint on the transient thermal analysis of the TPS. The TPS thickness is optimized to be the thinnest possible while not exceeding the allowable bondline temperature.

The dual layer system mass sensitivity to allowable bondline temperature is shown in Figure 8. All masses are normalized to the required TPS mass at the baseline allowable bondline temperature of $550{ }^{\circ} \mathrm{F}$. As with initial temperature, the ablator mass is not very sensitive to the allowable bondline temperature (less than $0.1 \%$ decrease in mass per $10{ }^{\circ} \mathrm{F}$ increase in allowable bondline temperature). The tile mass, however, is quite sensitive to allowable bondline temperature up to about $650^{\circ} \mathrm{F}$. After $650^{\circ} \mathrm{F}$ the sensitivity drops off because the allowable temperatures of the underlying structure start to become the driving constraint on the thickness optimization rather than the bondline temperature. For the portion of the analysis between 500 and $650{ }^{\circ} \mathrm{F}$, the tile mass sensitivity is relatively linear at approximately $1.5 \%$ mass savings per $10^{\circ} \mathrm{F}$ increase in allowable bondine temperature. This results in an overall dual layer system mass savings of approximately $0.5 \%$ per $10^{\circ} \mathrm{F}$ increase in allowable bondline temperature.

As a point of interest, the reason that the ablator sensitivity to allowable bondline temperature is not zero is because there are some cases in the very low heating areas of the dual layer system where the ablator thickness optimization is being driven by the bondline temperature rather than the tile allowable surface temperature.

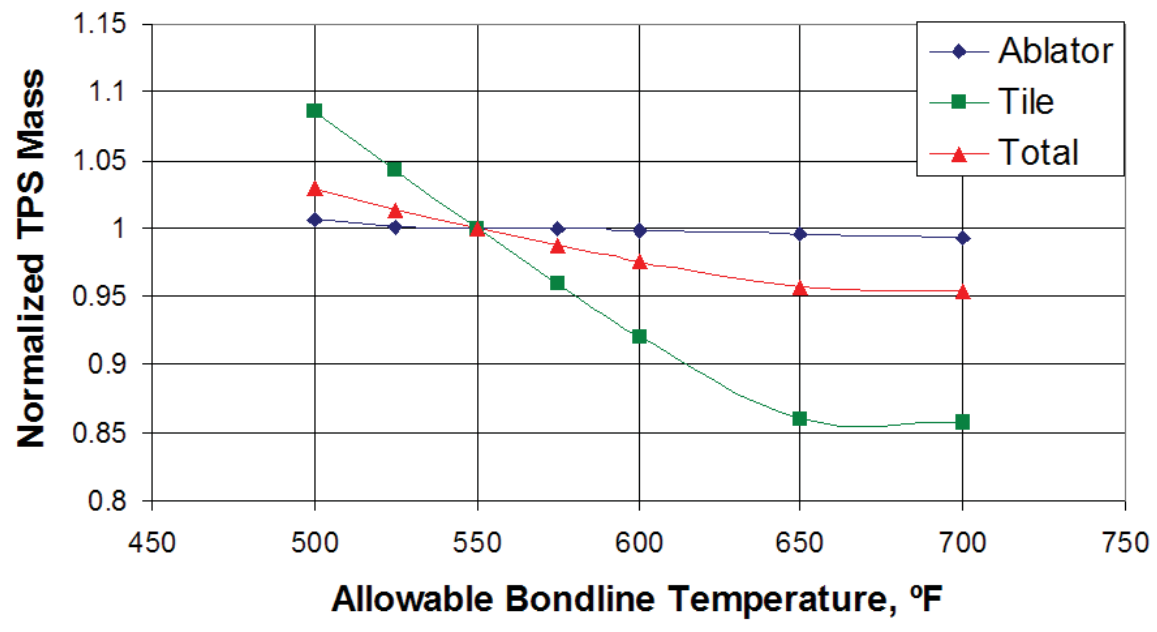

Figure 8. Sensitivity of Dual Layer Mass to Bondline Allowable Temperature

\section{Allowable Tile Surface Temperature}

For dual layer TPS analysis, in addition to the allowable bondline temperature, there is a constraint on the allowable tile (or insulator) surface temperature. The value is based on published single use temperatures for the insulator.

Figure 9 shows the dual layer system mass sensitivity to the allowable tile surface temperature. For this analysis the tile shows little mass sensitivity. However, the ablator thickness is quite sensitive with an approximately $0.3 \%$ decrease in required ablator mass for every 10 Kelvin increase in maximum allowable tile surface temperature if a linear approximation is used. This results in an overall dual layer system mass savings of about $0.2 \%$ for every 10 Kelvin increase in allowable tile surface temperature. 


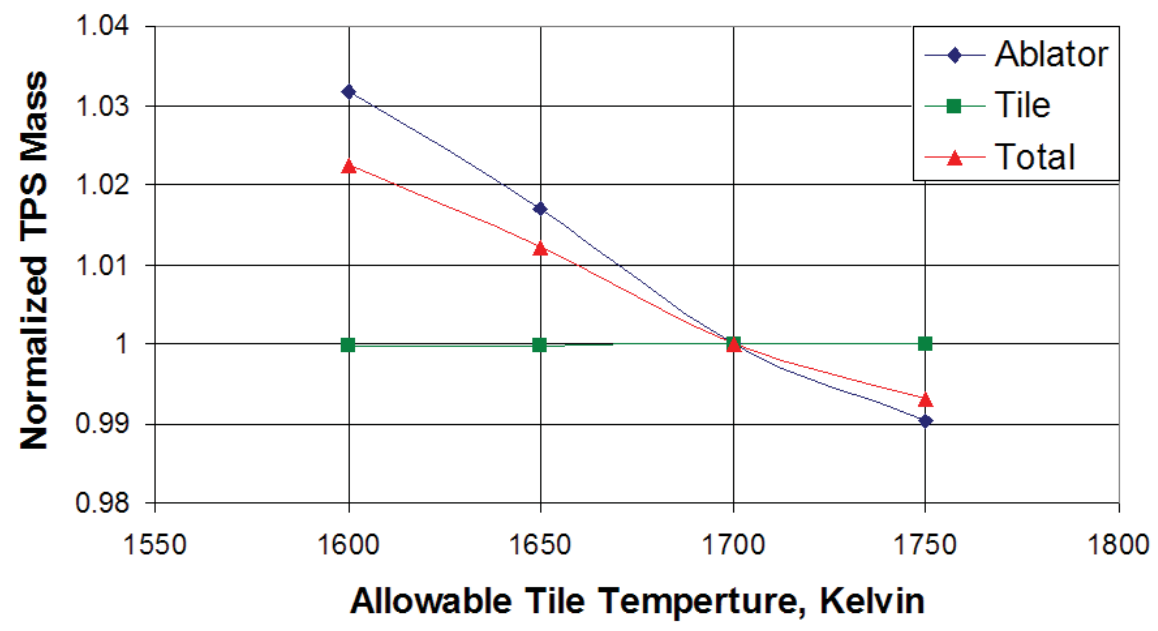

Figure 9. Sensitivity of Dual Layer Mass to Allowable Tile Surface Temperature

\section{Ablator Fail Lien}

Ablator fail lien is used to simulate additional material removal from the ablator surface due to mechanical causes ${ }^{10}$. The baseline value of $50 \%$ is taken from the margin process and is based on expert opinion of a current best guess.

The sensitivity of the dual layer TPS system mass to the ablator fail lien is shown in Figure 10. All masses are normalized to the mass from the analysis run with the baseline fail lien of $50 \%$. As would be expected, the ablator mass is extremely sensitive to the ablator fail lien at about an $0.6 \%$ ablator mass increase per $1 \%$ increase in fail lien. The tile mass is not sensitive to ablator fail lien, hence the resulting sensitivity of the overall dual layer system mass is approximately $0.44 \%$ increase in mass per $1 \%$ increase in ablator fail lien.

\section{E. Thermal Margin}

The bondline thermal margin is intended to capture uncertainties in the bondline temperature due to material response modeling uncertainties ${ }^{10}$.

Results of the sensitivity study of dual layer TPS mass to thermal material margin are shown in Figure 11. All mass results are normalized to the mass at the baseline 60 Kelvin. The ablator thickness is only slightly affected by increases in thermal margin (less than $0.05 \%$ mass increase per 10 Kelvin increase in thermal margin). The tile sizing is much more sensitive showing a $2.6 \%$ increase in mass for every 10 Kelvin increase in thermal margin. This results in an overall dual layer system sensitivity of approximately $0.8 \%$ mass increase per 10 Kelvin increase in thermal margin. 


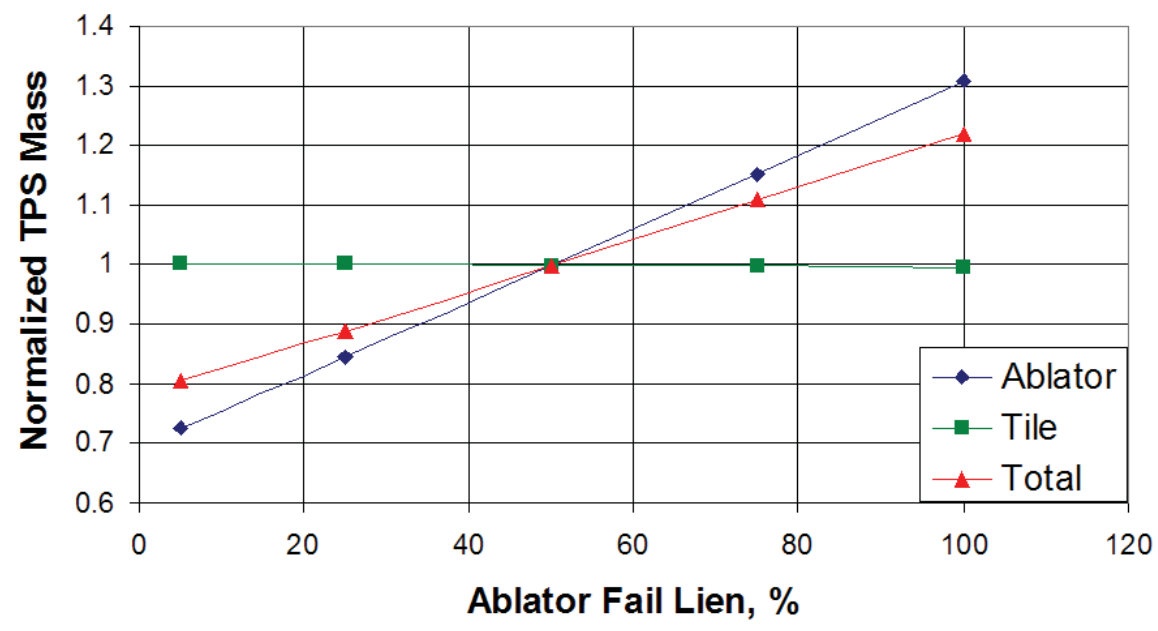

Figure 10. Sensitivity of Dual Layer Mass to Ablator Fail Lien

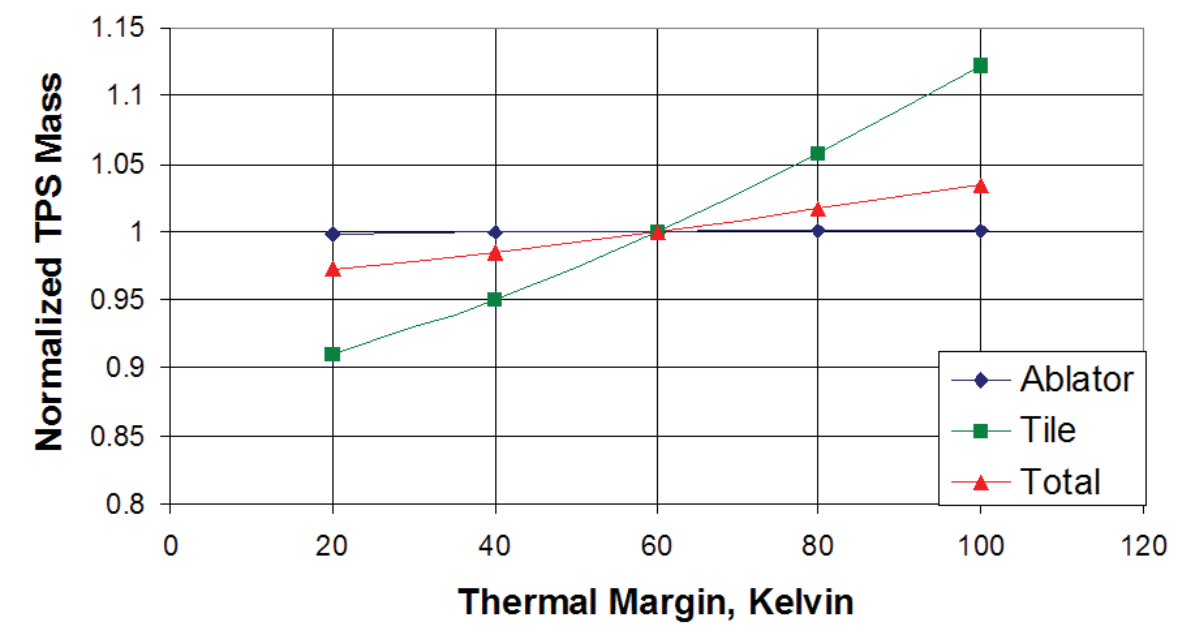

Figure 11. Sensitivity of Dual Layer Mass to Thermal Mass

\section{F. Structure Thermal Mass}

As discussed, two different cases were studied to understand the impact of the structural thermal mass on the dual layer TPS mass. First a parametric sweep was made of the titanium plate thickness to represent different thermal mass equivalents of the same material. Second the thickness was held and a sweep was made of several common structural materials. For the second case, a case was also run using a titanium honeycomb structure similar to CEV.

Figure 12 shows the results of the first study, the sensitivity of the dual layer TPS mass to equivalent mass of varying thicknesses of titanium plate. The ablator mass is not very sensitive to the structure equivalent thermal mass, but the tile mass is quite sensitive. The sensitivity increases as the equivalent thermal mass decreases. 
The sensitivities to structure material are shown in Figure 13. The masses for the tiles increased when switching to aluminum or graphite BMI but stayed approximately the same for stainless steel. This is due to the lower allowable temperatures of aluminum and graphite BMI. In addition, a CEV type titanium honeycomb structure was analyzed. The results of that run are very similar to the 0.06 ” titanium plate results. This indicates that a 0.06 ” titanium plate was a reasonable choice for an equivalent thermal mass given that the details of the structure design were not known at the time of this study.

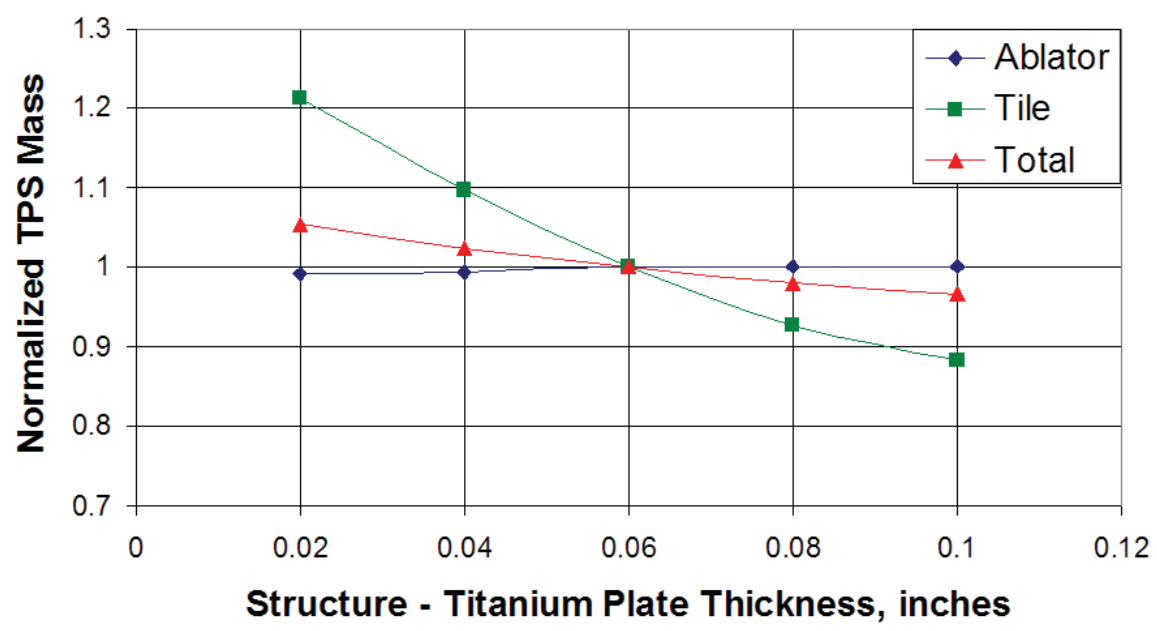

Figure 12. Sensitivity of Dual Layer Mass to Structure Thickness.

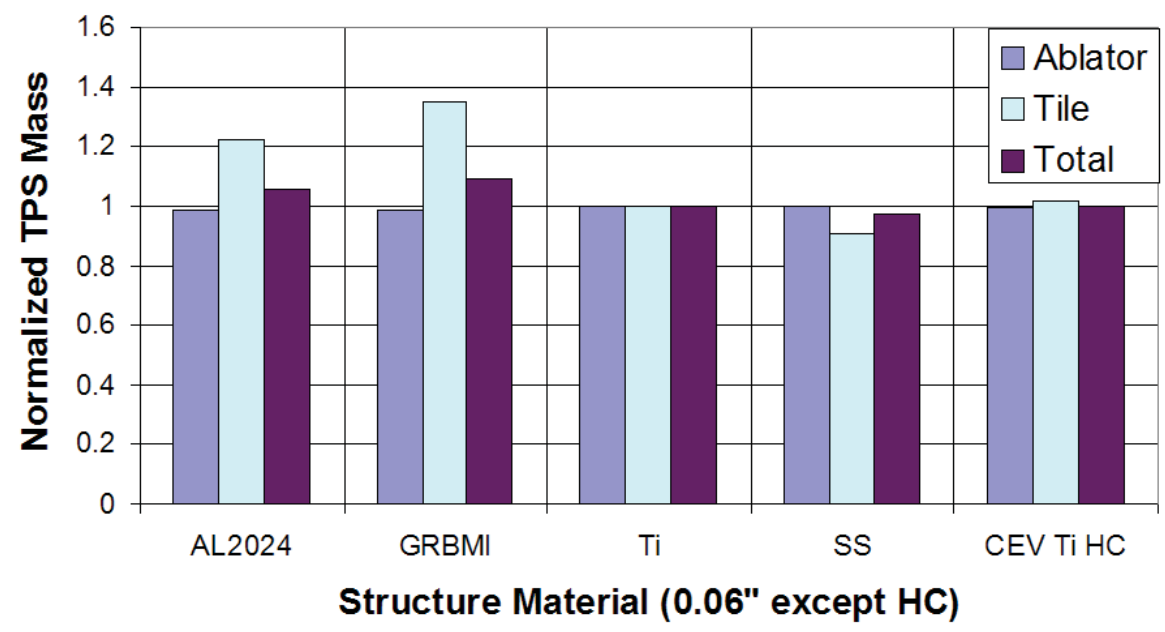

Figure 13. Sensitivity of Dual Layer Mass to Structure Material. 


\section{G. Soak out - Heat Shield Ejection Time}

The tile sizing is sensitive to how long the heat pulse is given to soak back to the bondline and underlying structure. Since the tile has low thermal conductivity, the time for the bondline to reach its maximum temperature can sometimes occur at a time much later than when the TPS surface experienced the heat pulse. Because of this, the tile sizing is often partially determined by how long a duration the analysis is run. Normally, maintaining the bondline temperature limit is important until the heatshield is ejected. For this analysis, the baseline heat shield ejection time was at the end of the trajectory or at Mach 0 . However, the design baseline for the nominal case is that the heatshield will be ejected at Mach 2.9 and the earliest assumption is that the heat shield will be ejected at Mach 5. So, a sensitivity was run using heat shield ejection points from Mach 5 down to Mach 0 (touchdown). The sensitivities are presented in Figure 6. The ablator sizing is not very sensitive to heat shield ejection time because this sensitivity is purely driven by the atmospheric entry portion of the trajectory when most or all of the ablator has ablated away. The mass sensitivities in the range studies are not linear, but are roughly a $1.1 \%$ decrease in tile mass and $0.3 \%$ decrease in system mass per Mach number increase in the heat shield ejection time.

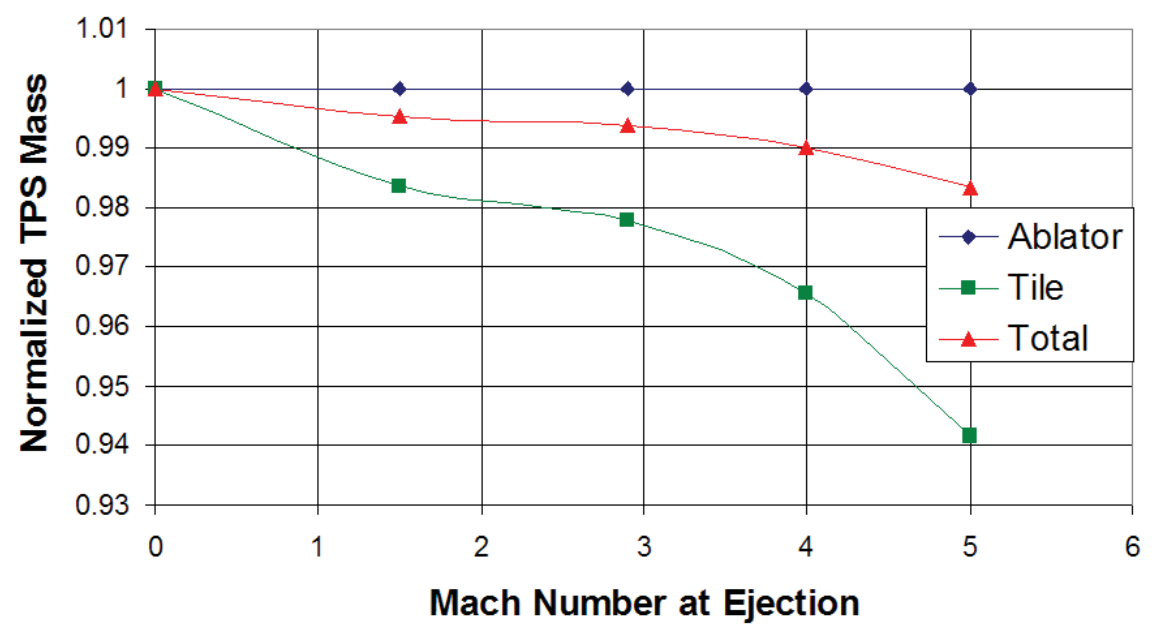

Figure 14. Sensitivity of Dual Layer Mass to Heat Shield Ejection Time

\section{H. Number of Heat Load Zones}

The material splitlines for the rigid mid L/D aeroshell were shown in Figure 2. These splitlines can be further split into sub-zones if a variable thickness TPS is desired to save mass. This is done by dividing the material splitlines regions into sub regions of similar integrated heat load. For the nominal sizing analysis, it was assumed that the TPS thickness could be varied on the vehicle and each material splitline was divided into 5 sub-zones by integrated heat load. These sub-zones are shown in Figure 15. A trade study was run on varying the number of heat load sub-zones per splitline region from 1 to 20 sub-zones. The results are shown in Figure 16. The TPS masses are quite sensitive to the initial division of sub-zones (from 1 to 5 sub-zones). After 5 sub-zones, the sensitivity decreases but is still contributing. 


\section{Sizing Regions $10 \times 29$}

Nominal Case with 5 splits per material region

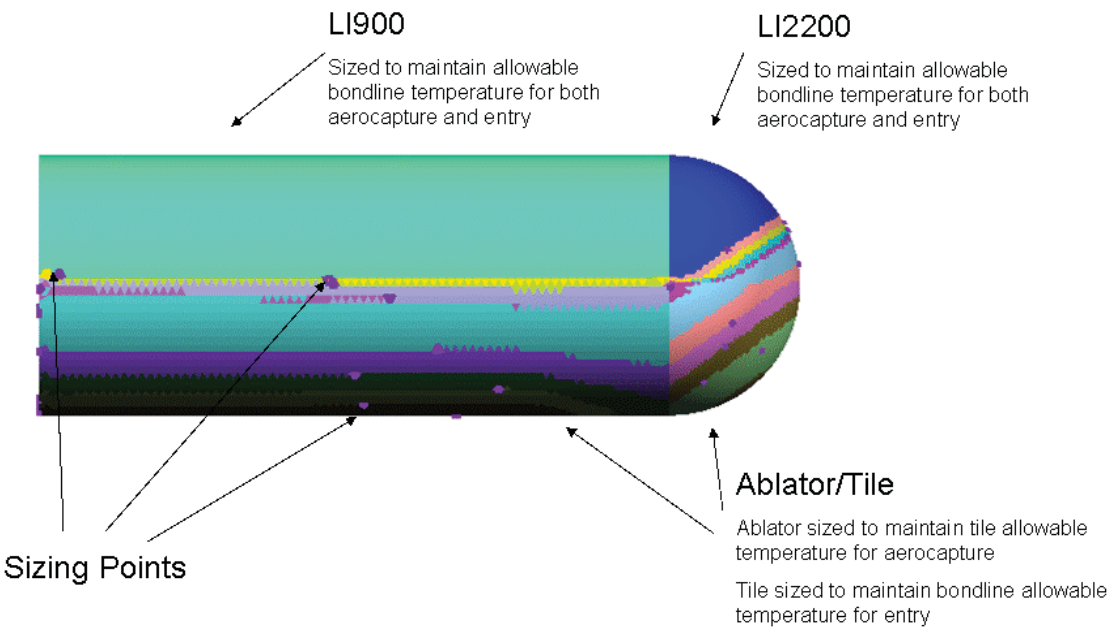

Figure 15. Sizing Region Subzones.

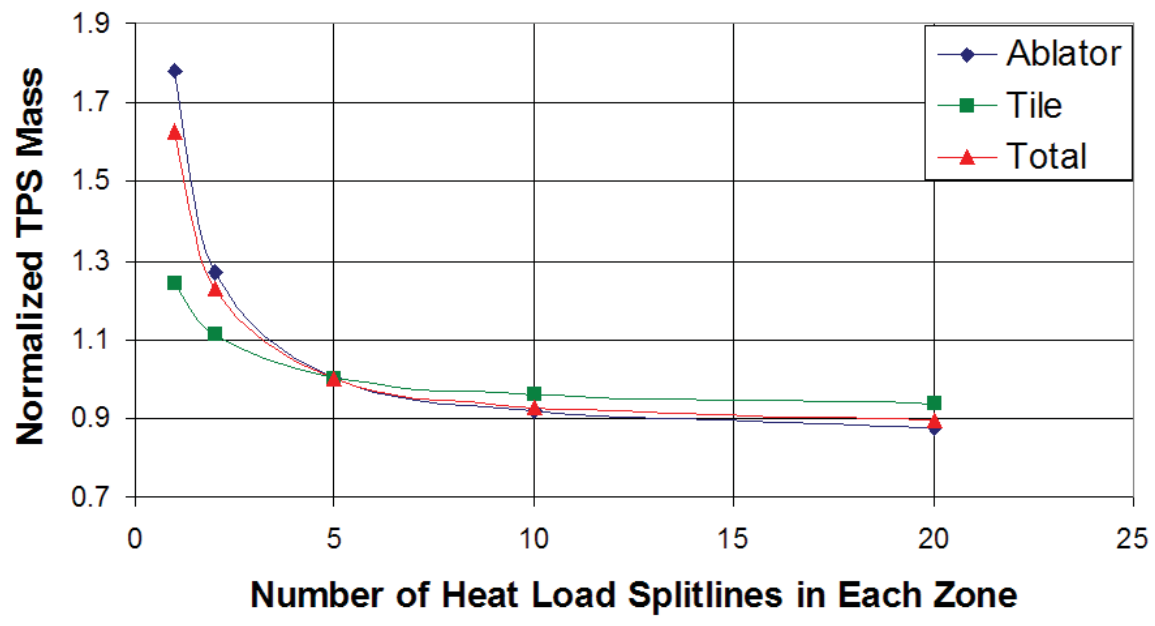

Figure 16. Sensitivity of Dual Layer Mass to Number of Heat Load Defined Splitlines

\section{Aerothermal Margins}

Aerothermal margins are used to capture the uncertainties in the modeling of the aerothermal environments. They are applied as multiplicative factors on the heating.

The sensitivities of dual layer TPS mass to aerothermal margin variations are shown in Figure 17. The margins were varied by applying a multiplier $(1.00,1.10$ and 1.20$)$ to the nominal convective heating margin of 1.35 . Both the tile and the ablator were sensitive to changes in aerothermal convective heating margin. The ablator saw a $1.0 \%$ mass increase per $1 \%$ increase in aerothermal convective heating margin. For the tile the increase was $0.1 \%$ per $1 \%$ increase in margin. This results in an approximate increase of $0.8 \%$ in the overall dual layer system mass per $1 \%$ increase in aerothermal convective heating margin. 


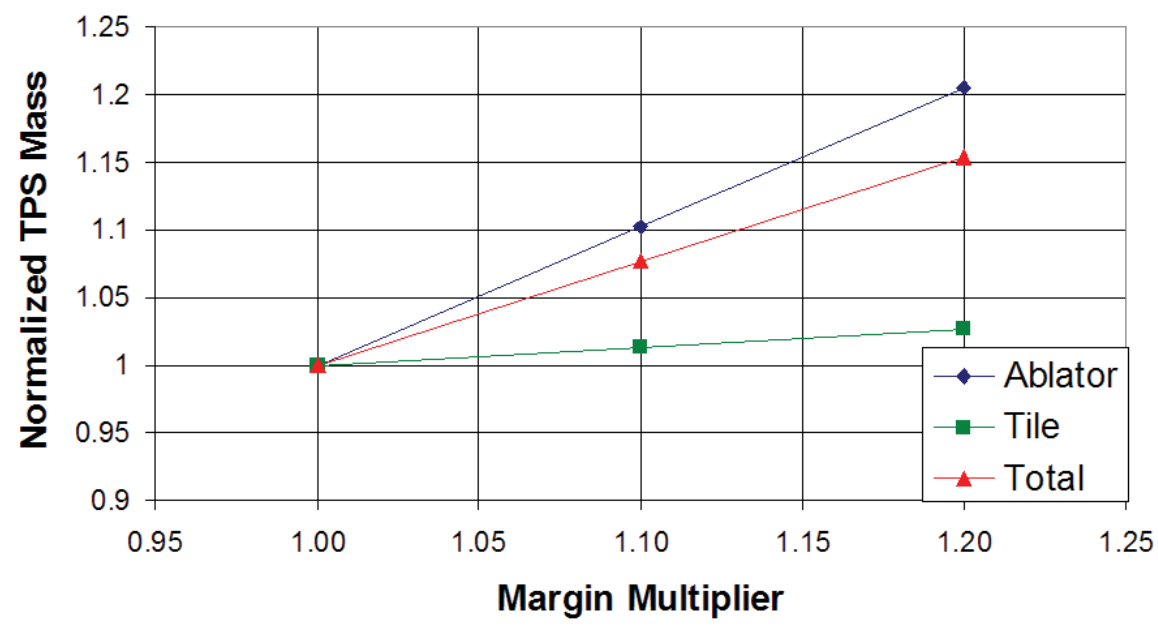

Figure 17. Sensitivity of Dual Layer Mass to Aerothermal Convective Heating Margin (1.35 Nominal, $1.1 * 1.35-1.485,1.2 * 1.35=1.62$ )

\section{J. Trajectory Dispersion Margins}

Similar to the aerothermal margins, the trajectory dispersion margins are used to capture uncertainties in the trajectory calculations. They are also applied as multipliers on the applied heating.

The sensitivities of dual layer TPS mass to trajectory dispersion margin variations are shown in Figure 18 . The margins were varied by applying a multiplier (1.00, 1.10 and 1.20) to the nominal trajectory dispersion heating margin of 1.35. Both the tile and the ablator were sensitive to changes in dispersion heating margin, with the ablator being more sensitive. The ablator saw a 1.15\% mass increase per 1\% increase in dispersion heating margin. For the tile the increase was $0.3 \%$ per $1 \%$ increase in margin. This results in an approximate increase of $0.9 \%$ in the overall dual layer system mass per 1\% increase in trajectory dispersion heating margin.

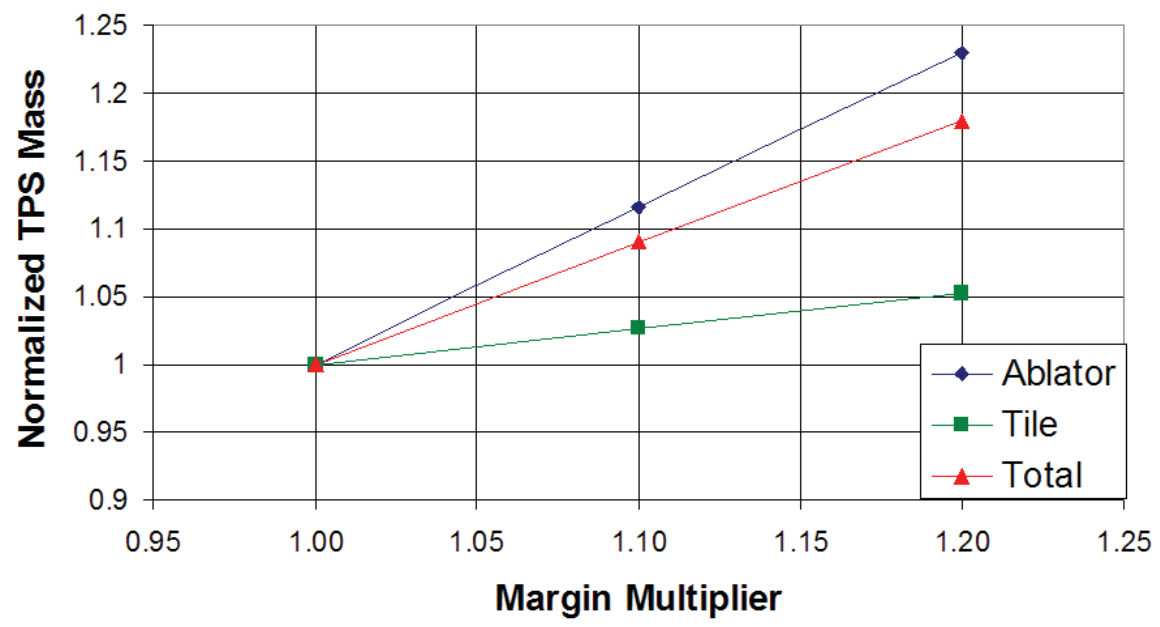

Figure 18. Sensitivity of Dual Layer Mass to Trajectory Heat Load Dispersion Margin (1.35 Nominal, $1.1 * 1.35-1.485,1.2 * 1.35-1.62)$ 


\section{Conclusions}

A methodology and code upgrade to automate the sizing optimization of a dual layer ablator over insulator TPS system was developed during the EDL-SA studies conducted during FY09. The TPS sizing results presented here were shown to be similar to those produced during DRM5 and demonstrate the credibility of providing the TPS for the 10 by 29 meter Mid L/D aeroshell for future human Mars missions. The use of a $5 \mathrm{~cm}$ honeycomb for the windward TPS installation appears to enable the manufacture of the large heat shield while still maintaining mass savings as compared to a monolithic ablator system.

The upgraded TPSSizer code was also used to conduct several sensitivity studies to understand the assumptions and margins used for the TPS Sizing analysis. Further upgrades to the TPSSizer code to allow for ablator protection of the insulator during the atmospheric entry portion of the mission are planned for FY11.

\section{Acknowledgments}

The efforts described herein were aided by valuable discussions with Jeff Bowles who performed the hand analysis of the dual layer concept during the DRA5 TPS studies. The work of Dave Kinney in creating the aerothermal database is also acknowledged. The author also appreciates the support of James Arnold and Ethiraj Venkatapathy for the study of the dual layer, dual heat pulse TPS concept.

\section{References}

${ }^{1}$ NASA Entry, Descent and Landing Competencies, Program Decision Memorandum. s.l. : AMO OCE Issue \#3, Aug. 19, 2008.

2 "Entry, Descent and Landing Long Term Capability Requirements Evaluation Terms of Reference (TOR)”. s.l. : Office of the Chief Engineer Memorandum, Oct, 2008.

${ }^{3}$ Drake, B. G., editor. Human Exploration of Mars Design Reference Architecture 5.0. s.l. : NASA-SP-2009-566, July 2009.

${ }^{4}$ D wyer-Cianciolo, A. M., et al., "Entry, Descent and Landing Systems Analysis Study: Phase 1 Report,” NASA-TM-2010216720, July 2010.

${ }^{5}$ McGuire M. K., Bowles J., Yang L., Kinney D., Roberts C., “TPS Selection and Sizing Tool Implemented in and Advanced Engineering Environment,” AIAA-2004-342, 42 ${ }^{\text {nd }}$ AIAA Aerospace Sciences Meeting and Exhibit, Reno NV, Jan. 2004.

${ }^{6}$ William M. Congdon (ARA Ablatives Laboratory) "Development of Design and Production Processes for a Block-Ablator Heatshield with Preliminary Test Results,” International Planetary Probe Workshop, Barcelona Spain, June 12-18, 2010.

${ }^{7}$ Zell, P. T., Venkatapathy E., and Arnold, J. O., “The Block-Ablator in a Honeycomb Heatshield Architecture," $7^{\text {th }}$ International Planetary Probe Workshop, Barcelona, Spain, June 12-18, 2010.

${ }^{8}$ Arnold, J. O., Venkataphy, E., Sepka S., Agrawal, P., Chen, Y. K., "Validation Testing of a New Dual Heat Pulse, Dual Layer Thermal Protection System Applicable to Human Mars Entry, Descent and Landing," $7^{\text {th }}$ International Planetary Probe Workshop, Barcelona, Spain, June 12-18, 2010.

${ }^{9}$ Y.K. Chen and F.S. Milos, “Ablation and Thermal Response Program for Spacecraft Heatshield Analysis," Journal of Spacecraft and Rockets, Vol. 36, No. 3, 1999, Pp. 475-483.

${ }^{10}$ Wright M., "CEV Thermal Protection System (TPS) Margin Management Plan,” NASA-ARC, C-TPSA-A-DOC-7005, Rev. 2.0, Nov. 12, 2009.

${ }^{11}$ Kinney D., “Aero-Thermodynamics for Conceptual Design,” AIAA-2004-31, 42 ${ }^{\text {nd }}$ AIAA Aerospace Sciences Meeting and Exhibit, Reno NV, Jan. 2004.

${ }^{12}$ Kinney, D. J., "Aerodynamic and Aerothermal Environment Models for a Mars Entry, Descent, and Landing Systems Analysis Study,” 49 th AIAA Aerospace Sciences Meeting, Orlando, FL, January 4-7, 2011.

${ }^{13}$ Wright M. J., Chandler, G. V., and Bose, D., "Data-Parallel Line Relaxation Method for the Navier-Stokes Equations," AIAA Journal, Vol. 36, No. 9, 1998, pp 1603-1609.

${ }^{14}$ Davis, J. L., Cianciolo, A. D., Powell, R. W., Shidner, J. D. and Garcia-Llama, E., “Guidance and Control Algorithms for the Mars Entry, Descent and Landing Systems Analysis,” AIAA 2010-7972, AIAA/AAS Astrodynamics Specialist Conference, Toronto, Ontario Canada, August 2-5, 2010. 